\title{
QUANTITATIVE DUNKL ANALOGUE OF SZÁSZ-MIRAKYAN OPERATORS
}

\author{
QING-Bo CAI, SERdAl YAZICI, BAYRAM ÇEKIM* AND GÜRHAN İÇÖZ
}

Abstract. The main object of this paper is to introduce a sequence of quantitative Dunkl analogue Szász-Mirakyan operators. Firstly, we have defined mentioned operators and have obtained test values and central moments for our operators. We have given weighted Korovkin theorem for these operators and then, have shed light on approximation properties of these operators with the help of the classical modulus of continuity, Peetre's $K$-functional, the second modulus of continuity, the modulus of weighted continuity defined by Holhos in [30] on some function space. Moreover, we have given Voronovskaya type theorems for our operators and basic operators defined by Sucu in [6]. Finally, graphics of these operators have been presented for some values of $n$.

Mathematics subject classification (2020): 41A25, 41A36.

Keywords and phrases: Dunkl exponential, Szász operators, Modulus of continuity, Voronovskaya type asymptotic formula.

\section{REFERENCES}

[1] A. ARAL, A generalization of Szász-Mirakyan operators based on q-integers, Mathematical and Computer Modelling, (2008), 47 (9-10), 1052-1062.

[2] S. VARma And F. TAŞDelen, Szász type operators involving Charlier polynomials, Mathematical and Computer Modelling, (2012), 56 (5-6), 118-122.

[3] O. DumAn AND M. A. ÖZARsLan, Szász-Mirakjan type operators providing a better error estimation, Applied Mathematics Letters, (2007), 20 (12), 1184-1188.

[4] O. Duman, M. A. Özarslan And B. D. Vecchia, Modified Szász-Mirakjan Kantorovich operators preserving linear functions, Turkish Journal of Mathematics, (2009), 33, 151-158.

[5] V. TотіK, Approximation by Szász-Mirakjan-Kantorovich operators in $L^{p}(p>1)$, Analysis Mathematica, (1983), 9 (2), 147-167.

[6] S. Sucu, Dunkl analogue of Szász operators, Applied Mathematics and Computation, (2014), 244: 42-48.

[7] M. Rosenblum, Generalized Hermite polynomials and the Bose-like oscillator calculus, Oper. Theory: Adv. Appl, (1994), 73, 369-396.

[8] G. İÇÖZ AND B. ÇEKIM, Stancu-type generalization of Dunkl analogue of Szász-Kantorovich operators, Mathematical Methods in the Applied Sciences, (2016), 39 (7), 1803-1810.

[9] G. İÇÖZ AND B. ÇEKIM, Dunkl generalization of Szász operators via q-calculus, Journal of Inequalities and Applications, (2015), 1-11.

[10] M. Nasiruzzaman and A. M. Aljohani, Approximation by parametric extension of SzászMirakjan-Kantorovich operators involving the Appell polynomials, Journal of Functions Spaces, (2020), Volume 2020, Article ID 9657489.

[11] M. Nasiruzzaman And N. RaO, A generalized Dunkl type modifications of Phillips operators, Journal of Inequalities and Applications, (2018), 323.

[12] M. Nasiruzzaman And A. M. Aljohani, Approximation by Szász-Jakimovski-Leviatan type operators via aid of Appell polynomials, Journal of Functions Spaces, (2020), Article ID 9657489. 
[13] M. Nasiruzzaman, Approximation properties by Szász Mirakjan operators to bivariate functions via Dunkl analogue, Iranian Journal of Science and Technology (Transactions A: Science), (2020), https://doi.org/10.1007/s40995-020-01018-8.

[14] H. M. Srivastava, M. Mursaleen, A. M. Alotaibi, M. Nasiruzzaman, A. A. H. AlABIED, Some approximation results involving the q-Szász-Mirakjan-Kantorovich type operators via Dunkl's generalization, Mathematical Methods in the Applied Sciences, (2017), 40 (15), 5437-5452.

[15] M. Mursaleen, M. Nasiruzzaman, A. Alotaibi, On modified Dunkl generalization of Szász operators via q-calculus, Journal of Inequalities and Applications, (2017), 38.

[16] M. Mursaleen, S. Rahman, A. Alotaibi, Dunkl generalization of q-Szász-Mirakjan Kantorovich operators which preserve some test functions, Journal of Inequalities and Applications, (2016), 317.

[17] D. CÁRdenas-Morales, P. GARRAncho, I. RASA, Bernstein-type operators which preserve polynomials, Computers and Mathematics with Applications, (2011), 62, 158-163.

[18] T. ACAR, Asymptotic formulas for generalized Szász-Mirakyan operators, Applied Mathematics and Computation, (2015), 263, 223-239.

[19] M. Murs ALEen AND S. Rahman, Dunkl generalization of q-Szász-Mirakjan operators which preserve $x^{2}$, Filomat, (2018), 32 (3), 733-747.

[20] T. ACAR AND G. Ulusoy, Approximation by modified Szász-Durrmeyer operators, Periodica Mathematica Hungarica, (2016), 72: 64-75.

[21] A. Aral, D. InOAn And I. RaşA, On the generalized Szász-Mirakyan operators, Results in Mathematics, (2014), 65 (3-4), 441-452.

[22] P. P. Korov KIn, Convergence of positive linear operators in the space of continuous functions, (Russian) Doklady Akademii Nauk SSSR, (1953), 90, 961-964.

[23] A. D. GADZHIEV, The convergence problem for a sequence of positive linear operators on unbounded sets and theorems analogues to that of P. P. Korovkin, Soviet Mathematics Doklady, (1974), 15(5): $1453-1436$.

[24] G. V. Milovanović, M. Mursaleen, M. Nasiruzzaman, Modified Stancu type Dunkl generalization of Szász-Kantorovich operators, RACSAM, (2018), 112, 135-151.

[25] F. Altomare And M. CAmpiti, Korovkin-Type Approximation Theory and Its Applications, De Gruyter Studies in Mathematics 17, W. De Gruyter, Berlin-New York, (1994).

[26] R. A. DeVore and G. G. Lorentz, Constructive Approximation, Springer-Verlag, Berlin Heidelberg, (1993).

[27] P. L. Butzer And H. Berens, Semi-Groups of Operators and Approximation, Springer, BerlinHeidelberg-New York (1967).

[28] D. Cárdenas-Morales, P. Garrancho, I. RaşA, Asymptotic Formulae via a Korovkin-Type Result, Abstract and Applied Analysis, (2012), Article ID 217464.

[29] N. İsPIR, On modified Baskakov operators on weighted spaces, Turkish Journal of Mathematics, (2001), 25 (3), 355-365.

[30] A. Holhos, Quantitative estimates for positive linear operators in weighted spaces, General Math, (2008), 16 (4), 99-110. 